\title{
Forensic Mental Health Nursing in Secure Hospitals and the Criminal Justice System
}

\section{Byrt R*}

School of Nursing and Midwifery, De Montfort University, UK

*Corresponding author: Richard Byrt, The North Bridge Tavern 1, Frog Island Leicester LE3 5AG, UK, Tel: 0116251 0871; Email: byrtrichard@yahoo.co.uk

\section{Review Article \\ Volume 3 Issue 1}

Received Date: February 02, 2019

Published Date: February 18, 2019

\section{Abstract}

Aim: The paper aims to review literature, including research studies, on forensic mental health (FMH) nursing.

Method: Literature searches were conducted, using Cumulative Index for Nurses and Allied Health Literature (CINAHL), and other databases and sources. Most papers on FMH nursing, from these sources, are North American, European and Australasian.

Results: The literature includes accounts, and related research, on FMH nurses' increasing involvement in relatively new services. Nurses have designed, validated and used risk assessment tools, and managed risk, but research has found that some service users experience problems from excessive risk management. There is evidence of the importance of communication to forensic service users, with many accounts of this topic. Research findings suggest the need for FMH nurses' self-awareness, and the importance of meeting service users' needs related to beneficial ward environments, physical health, cultural and other holistic needs, recovery and trauma-informed care. Research on initiatives to reduce seclusion use, and ethical issues, especially related to "security and therapy" roles are described in the literature, as are nurses' interventions using cognitive behavioral therapy (CBT). There are mixed reports on the efficacy of CBT with service users experiencing schizophrenia, and findings indicating its efficacy in anger management.

Limitations and Conclusions: This is an overview of aspects of forensic nursing often considered in relevant literature, rather than a systematic review. Accounts of FMH nursing in the literature surveyed may not reflect relevant practice, including communication, in non-Western societies. There is a need for systematic reviews of FMH nursing, including literature from non-Western countries.

Keywords: Forensic Mental Health Nursing; Criminal Justice System; Secure Hospitals; Risk Assessment; Nurse-Patient Communication; Holistic Care; Ethics; Cognitive-Behavioral Therapy

\section{Introduction}

This paper aims to review literature, including research studies, on forensic mental health (FMH) nursing, particularly in the UK. This area of practice is concerned with the assessment and care of the minority "...of individuals whose mental health problems are associated with offending behaviours..." [1]. However, research has found that most people who experience mental health problems do not commit violent or other offences [2]. 


\section{Nursing \& Healthcare International Journal}

Literature searches included Cumulative Index for Nursing and Allied Health Literature (CINAHL), and to a lesser extent, MEDLINE, PsycARTICLES, PsycINFO, and hand searches. Research studies and descriptive accounts of FMH nursing were surveyed. It has been argued that FMH nursing has a limited evidence-base [3]. Although there are many research studies in FMH nursing, the majority have limited generalizability, requiring nurses' judgement about the applicability of findings to their own practice. However, generalizable results of some research, conducted by other professionals, are relevant to $\mathrm{FMH}$ nursing [4].

Most of the readily available literature on FMH nursing appears to be North American, Australasian and European, with comparatively little literature from other continents. This may be because the latter is not included in the databases searched, or reflect the lack of secure and other mental health services, including prison health care, for people in some nations [5]. Most of the present account is based on Western ideas about FMH nursing and services, which may be seen as inapplicable in some countries, in which there may be other, equally valid, ideas about what constitutes good nursing care and communication [6].

\section{Areas where Forensic Mental Health Nurses Work}

In much of the world, people with mental health problems who offend are imprisoned, sometimes with little treatment and care [5]. In some countries, these individuals may be admitted to secure hospitals, run by prison or health service administrations. England has high, medium and low secure hospitals, for service users with varying amounts of risk, including people transferred from prison. Individuals with violent behaviours are sometimes admitted to low or medium secure units from generic mental health services. Service users are often transferred to lower levels of security before being discharged into the community [7].

In England, FMH nurses also work in the community with service users after their discharge from secure hospitals, often under "conditional discharge orders" under the Mental Health Act, 1983 [8]. Community FMH nurses also work with people convicted of minor offences, including individuals with "a community sentence with a mental health treatment requirement" [7].

\section{Court and Police Liaison and Diversion Services}

In the UK, FMH nurses are also based in court and police liaison and diversion services. Their work includes assessments of service users' mental health problems, and of risks to themselves and/or others; referral to services for care and treatment; and liaison with health and other professionals, including probation officers, the police and magistrates. Liaison and diversion services aim to provide early intervention, prevent more serious mental health problems, and divert people from arrest, prison, and secure hospital admission $[9,10]$. Often, assessments have to be conducted within limited time, requiring skills in quickly establishing rapport and effective communication [9]. In addition, some FMH nurses work with police in "triage services", accompanying them to mental health emergencies: for example, an individual who is very distressed, and attempting to assault others in response to voices (auditory hallucinations). One such triage service is available every day of the year, and enables people to access mental health care and treatment, rather than being detained in police cells [11].

One study found that nursing input for people detained in police stations, improved the care that these individuals received, and enhanced safety [12]. In other research, it was discovered that collaboration between mental health professionals and police improved service users' referral to "mental health services" [13].

\section{Nursing Prisoners and Ex-Prisoners}

"One in four" UK prisoners "have a severe mental illness", and imprisonment "increase[s]... risk of suicide and self-harm" [14], and can worsen mental health problems [15]. In England, mental health nurses are employed by either the Prison Service, or Health Services, who supply nurses for assessments and interventions (for example, cognitive behavioural therapy, described later in this article, with people who self-harm) [16]. However, the number of prisoners committing suicide and selfharm has increased, with increasingly adverse environments in some prisons. Problems include bullying and violence by prisoners, ready access to harmful drugs, long periods of time in cells, and lack of activity [17]. In such environments, in the UK and globally, nurses find it difficult to provide care or prevent mental or physical ill health [18,19]. A human rights approach has been suggested to address lack of adequate health care in prisons [19], which, internationally, have large numbers of prisoners with mental health and drug-related problems [20].

Warren (2015) emphasizes the importance of nurses working with people experiencing mental health problems after they leave prison, given high rates of relapse and suicide rates following release. Nurses assess 


\section{Nursing \& Healthcare International Journal}

and meet service users' mental and physical health needs, and liaise with other professionals about needs for accommodation, financial benefits and other services [16]. Many of these service users are subject to "Multi-Agency Public Protection Arrangements" [21], which require nurses and other professionals to contribute to collaborative risk assessment and risk management [16].

\section{Nursing in Secure Hospitals}

The rest of this paper is concerned with nursing assessment and interventions in English secure hospitals, in which service users are almost always detained under sections of the Mental Health Act, 1983, with 2007 amendments, which enable service users to be admitted from courts and prisons [8,22], usually with multiple, complex mental health problems, including mental illness and/or personality disorder. (As children, many individuals with personality disorder have experienced serious abuse, and lack of attachment to parents and other adults, and they often find it hard to safely express very painful feelings [23]). In addition, most forensic service users have histories of problematic use of alcohol and/or other drugs [24]. It is also important that FMH nurses recognise service users' significant relationships, and their positive qualities and talents [25].

Kettles, et al. (2007) argue that FMH nursing assessment and interventions include the interconnection of: ensuring safety and reducing risk; relieving the individual's distress; and holistic care, "based on respect for the individual and his/her unique needs, including those related to culture, spirituality and diversity" [1]. However, authors vary in their views about the extent that it is possible to combine safety and security and therapeutic interventions in secure hospitals. This has been referred to as the "security/custody versus therapy debate". Some authors have argued that the two are opposed and cannot co-exist, and question the dual aims of secure hospitals to both provide care and treatment, and to protect the public [26]. Conversely, several FMH nurses have argued that, despite some conflicts, it is possible to provide services which are both secure, in order to ensure safety, and beneficial to the service user [27].

In secure hospitals, nurses and other professionals maintain safety through ensuring high standards of security [7], based on risk assessment and risk management [28]. Relational security involves the development of beneficial therapeutic nurse-service user relationships and communication, and a thorough knowledge of the service user, based on detailed assessment [29]. Physical security includes maintaining safe, secure environments, including, for example, procedural security for locking doors. Multidisciplinary and nursing interventions can also be seen as contributing to security and safety [7].

\section{Risk Assessment and Risk Management}

Risk has been defined as: “...The probability of a particular adverse event occurring..." [30]. Risk assessment evaluates the potential risk of the service user towards herself/himself, and other people, including the public, and factors which minimize or increase this risk [28]. Some authors argue that, in FMH nursing, good risk assessment and risk management are concerned with providing the least restrictive environment for the individual's assessed risk of harm to self and others; and with enabling freedoms compatible with safety, not just restrictions [31]. However, over the last few decades, there has been an increase in locked and secure mental health units in the UK, with some service users spending what appear to be unnecessarily long times in these environments [32], possibly because of limited alternative services and an increasing number of people being admitted from prison [33].

There are over 200 risk assessment tools, designed to assess risks of violence more accurately than clinical judgment alone [34]. Many of these have been produced, and tested for validity and reliability, by nurses or other professionals [28,35], although problems related to validation and other areas have been highlighted [34]. FMH nurses use risk assessment tools to document violent incidents [36], and identify relevant causative and contributory factors, and triggers [28]. Risk assessment tools include the Historical Clinical Risk Management-20 (HCR-20), which assesses risk related to past behaviors, clinical factors in the present, and future "risk management" [37]. Arai, et al. (2017) report research findings that the HCR-20 is effective at assessing risk in Japan and other parts of the world [38]. The Short-Term Assessment of Risk and Treatment (START) assesses both service users' "strengths", which may reduce their risk, and "violence to others...suicide...self-harm...self-neglect", absconding from inpatient services, problematic use of alcohol and/or other drugs, and risks of being victimized [39].

The literature on risk assessment also considers evaluation, by FMH nurses and other professionals, of the individual's past history and experiences $[7,28]$. Family history is assessed, in relation to childhood and later relationships with parents and other relatives; 


\section{Nursing \& Healthcare International Journal}

experiences of physical, sexual and emotional abuse; and significant people in the patient's life, including intimate partners. Risk assessment also includes the service user's experience of physical health problems from early childhood onwards. These occasionally influence violence or other offending: for example, because of acquired head injury. Other areas assessed include the service user's history of offending, arrests, convictions, and periods in prison. Details of the index offence (the offence resulting in admission to the secure hospital) are also collected, as are personality factors related to offending. Examples include being unnecessarily and excessively suspicious of other people, or having difficulty in controlling anger. Past and present psychiatric history is considered, including experience of specific mental illnesses and/or personality disorders, and symptoms particularly associated with offending, including delusions that other people are harming the service user; command hallucinations ordering assault on others; and features of antisocial personality disorder such as impulsivity and difficulties in experiencing empathy [40].

Very importantly, protective factors are assessed. These include the individual's strengths, abilities and positive coping strategies which she/he could be enabled to develop, in order to reduce risk $[35,41]$. These could include, for example, the service user's motivation to avoid future reoffending, support from a relative, and a willingness to understand why the offending occurred $[7,28]$.

\section{Assessing Problematic Substance Use}

In addition, several authors outline the need for assessment of problematic use of alcohol and other drugs [24], which considerably increases risks of violence $[42,43]$. High proportions of people in prisons [20] and secure hospitals [44] have histories of problematic substance use, frequently associated with offending, indicating the importance of treating this, as well as specific mental health problems. The nurse's nonjudgmental attitude is crucial. Service users' use of various substances is very understandable, as alcohol and cannabis may temporarily relieve symptoms such as distressing voices and delusions. However, substance use may worsen symptoms of schizophrenia, and possibly result in an alcohol or other drug-induced psychosis [45].

\section{Risk Management, Its Adverse Effects and Service User Collaboration}

Risk management includes ways to prevent and reduce risky behaviours to self and others. This is achieved through maintenance of safety, including levels of observation appropriate to the service user's assessed risks; therapeutic communication and relationships; meeting service users' needs holistically; and nursing and other professional interventions, such as cognitivebehavioral therapy, that address the causes of risky behaviors. Risk management is also concerned with the allocation of responsibilities to prevent risk; good communication with the service user and between all professionals involved; and careful planning of care, treatment and rehabilitation related to assessed risk [28].

The over-representation of black people in prisons and secure health services, as part of "institutional racism", highlights the need for risk assessments to be sensitive to people's culture, as well as gender, disabilities, age, sexual orientation and gender identity [46]. Some researchers have found that, in certain services, risk assessment is excessive, with ordinary, non-risky behaviours seen as "evidence" of risk [47-49]. Coffey (2012) found that some clients of forensic mental health community teams felt overwhelmed by the number of professionals involved in assessing and managing risk [47]. Some of these problems can be avoided through risk assessment and management that collaborates with service users, and sensitively considers their views, as well as those of their family (with service users' agreement) and a variety of professionals [41]. There may be marked differences of opinion, concerning levels of risk, between service users and staff, and these should be acknowledged [50]. However, nursing interventions can gradually enable some service users to monitor their risk and take steps to reduce this. An example concerns a young woman who eventually became able to manage voices commanding her to assault others, by deciding to use care planned strategies, which included discussing the voices with a nurse, engaging in activities that she enjoyed, such as art and physical exercise, and a "when required" (PRN) antipsychotic, in addition to her regular medication [1].

\section{Safe, Therapeutic Environments}

Facilitating ward environments which are both safe and therapeutic, also contributes to effective risk management [23]. This includes activities that service users find meaningful and fulfilling, with prevention of boredom [51], including physical exercise, which can help channel aggression [52]; and opportunities for service users to discover their aptitudes and talents [25]. Research has found that forensic service users benefit from ward environments that are safe, with opportunities for communication and support from their peers, enabled by staff [53]. Some secure hospital wards and prison 


\section{Nursing \& Healthcare International Journal}

wings are run as modified therapeutic communities, in which all aspects of service users' social environment are intended to be beneficial. Events occurring in everyday living are examined in community meetings and in group psychotherapy, with individuals learning about themselves and their problems by considering instances when, for example, they had difficulty managing anger [54].

In addition, the FMH nurse's role in ensuring service users' rights and enabling access to legal and voluntary organisation advocates is particularly important $[31,55]$. Some authors stress the need for FMH nurses to enable service users to express views about their care and treatment, through surveys and patients' forums with managers, and, where possible, incorporate their suggestions in care plans and nursing interventions $[56,57]$.

\section{Forensic Nurses' Self-Awareness}

Several researchers identify the need for FMH nurses' self-awareness. In one study, it was found that some nurses' unreflective constructions of certain service users only as "evil", interfered with their ability to communicate, or work with them [58]. This was also found in another study, where FMH nurses' "negative attitudes" reinforced service users' problematic behaviours. However, other nurses found effective ways of working with these individuals, through, for example, commitment to caring, and understanding that service users' behaviors indicated underlying problems [59]. Other research found that prison nurses were, understandably, often troubled by prisoners' accounts of their offences. These studies indicate the need for clinical supervision to assist prison nurses to work professionally and non-judgmentally with prisoners $[60,61]$.

\section{Therapeutic Communication and \\ Importance to Forensic Service Users}

Its

Aims of effective nurse-service user relationships and communication include: relieving the individual's distress, valuing her/him as an individual, and increasing selfworth and self-esteem [23]; enabling the service user to eventually work with the nurse on specific problems; and importantly, increase safety and reduce risky behaviors, partly through establishing trust [31]. Also important is an understanding of what aspects of communication the service user finds beneficial and respectful, in relation to her/his culture, languages spoken and styles of communication [6].
From a systematic review, Doyle, et al. (2017) found that, in several studies, forensic service users saw "therapeutic relationships" with nurses as crucial [62]. These are achieved partly through the nurse being approachable, and establishing beneficial non-verbal and verbal communication, including active listening and empathy [31,57]. Salzmann-Erikson, et al. (2016,) emphasize the importance of FMH nurses' listening to service users "to establish trust" [63]. In Bowen and Mason's (2012) study, FMH nurses saw their relationships with service users as the foundation of their work [64]. Other research has found that the efficacy of psychotherapies in forensic services depends on the quality of the therapist-service user relationship $[65,66]$. The literature also includes forensic service users' accounts of nurses' communication and therapeutic relationships that they found helpful, including listening, being non-judgmental [67], showing "compassion" and instilling hope [68].

However, a limitation of research findings on therapeutic communication and nurse-patient relationships, is that an approach that works with one forensic service user may not work with another because of specific, unique needs [69]. In addition, effective therapeutic communication styles appear to depend on nurses' personalities, and the extent that they are authentic [70]; and very importantly, on cultural factors, which will affect what the service user perceives as caring, empathetic and respectful communication [6]. These factors limit the extent that evidence in single studies can be used to draw conclusions about styles of communication that are beneficial to all forensic service users [4].

FMH nurses' empathy includes recognition of the trauma faced by both service users and victims/survivors of offences, including relatives [71,72]. Empathy also involves appreciation of service users' distressing experiences related to their mental health problems; and understanding the perceptions of some of them that they are not "ill", or prefer to see themselves as "prisoners", rather than "service users" [50]. FMH nurses can demonstrate empathy through taking practical action [73]. An example is a young man who did not wish to engage with staff, but did so after a FMH nurse took seriously his lack of hole-free footwear, and his need for "cool" trainers, and arranged funding for him to purchase these [74].

\section{Negotiation and "Finding Common Ground"}

FMH nurses can establish therapeutic relationships with service users who do not see themselves as ill, or as putting others at risk, through negotiation: attempts to 


\section{Nursing \& Healthcare International Journal}

find common ground, and shared agreement with at least some care-planned goals [75]. Bowen and Mason (2012, p3561) found, from their research, that FMH nurses often reported "skills in power-sharing and negotiation...with.... patients", including "not backing the patient into a corner" [64]. In another study, FMH nurses' respect and empathy for service users enabled them to successfully set limits to ensure safety [76]. This contrasts with Morrison's (1992) finding that nurses' rigid authoritarianism increased the likelihood of aggression [77].

"Finding common ground" relates to Fulford's argument for staff to listen carefully to service users' views, including those that disagree with notions of professional care [78]. It also involves respect for service users' possibly very different cultural and other experiences, and attempts to find areas that the service user agrees that she/he would like help with [75]. An example is a FMH nurse who used card games to forge a therapeutic alliance with an (initially uncommunicative) service user, and enabled him to contact advocates about his rights. This led to this individual gradually being able to work with the nurse and other professionals, including making suggestions about his care, which were agreed [1]. "Finding common ground" also includes sharing appropriate humour in conversations with forensic service users, thus maintaining therapeutic relationships [79].

\section{Trauma-Informed Care}

Many forensic service users have experienced severe trauma: for example, from physical, sexual or emotional abuse or neglect in childhood [80]. This has implications for therapeutic relationships and communication which enable service users to feel that FMH nurses consistently care for, and value them, and are there to support them through difficult experiences [23]. Service users usually experience considerable distress and crisis on admission to secure hospitals [56]. Loss of freedom and the experience of admission may result in post-traumatic stress disorder [81]. Individuals' trauma may be increased because of unexpected "restrictions to ensure safety...rejection from...family members", anxiety about sentencing by courts, possible restricted access to children, and loss of valued family and work roles and income [82]. Lehoczki, et al. (2016) refer to the trauma that some forensic service users experience after committing violent offences [83]. In addition, research findings suggest a link between "traumas in childhood" and "hallucinations and delusions within psychotic disorders" [84]. Other studies indicate that physical restraint, and seclusion in a locked room can result in "flashbacks" of previous abuse for some service users, and other adverse effects [85]. This indicates the need for projects to reduce these interventions as much as possible [86]: for example, through preventing violence by intervening at an early stage, and making it easy for service users to communicate with nurses [87]. Research indicates that factors contributing to the reduction of seclusion include: leaders to enable change; clear information about seclusion use; identifying early signs of imminent violence; staff development and education; not prescribing "when required" medication; and the use of recovery principles [88]. In addition, service user involvement in, and staff ownership of, projects to reduce seclusion are crucial $[89,90]$. However, there are varied or inconsistent findings across seclusion reduction studies in secure hospitals; and difficulty in establishing the relative effects of individual variables, with limited research in this area [89].

\section{Holistic Care}

It has been argued that "Hodge's Health Career Model" can be applied in secure hospitals to enble holistic care in FMH nursing [91]. Byrt (2008a, p80) outlined the need to assess and meet service users' needs related to physical health, culture, ethnicity, spirituality, "psychological...and psychosexual needs...advocacy", finances, and needs related to "gender, age, disability, sexual orientation and gender identity" [92]. Holistic care has been considered in relation to the wide range of needs of individuals with a "personality disorder" diagnosis in secure settings [93].

Some UK secure mental health services have, in the past, failed to meet the needs of service users of minority ethnic groups and women [94,95]. However, more recently, there has been an emphasis, in the literature, on providing assessment, care and treatment which takes account of people's needs related to diversity [93], for example, in relation to "preventing suicide in lesbian, gay, bisexual and transsexual prisoners" [96]. Attempts to provide culturally-sensitive and gender-sensitive secure services have been described $[54,55]$.

Research findings and government inquiries suggest the importance of assessing and meeting forensic service users' spiritual and cultural needs, and ensuring that risk assessment, and subsequent admission to secure services, are not affected by culturally biased assumptions [69]. The inquiry into the death of David Bennett in a secure hospital discovered failure to take seriously his complaints of racism from another service user, or to provide holistic care that met his cultural and other needs [94]. The importance of FMH nurses assessing "religious 


\section{Nursing \& Healthcare International Journal}

or spiritual issues or concerns" of importance to service users, and enabling them to find hope and meaning $[97,98]$ has been emphasised. Askola, et al. (2018) found that remaining hopeful was particularly important to service users in a secure hospital [56].

\section{Recovery and Psychosexual Needs}

Recovery has been seen as an important goal in Western mental health services in the sense of "rebuilding a meaningful and valued life" [99]. The role of the FMH nurse, in relation to recovery, is partly to enable service users to achieve valued goals, often including preparation for their move to services with less security, or within the community. Recovery may relate to forensic service users' aspirations related to relationships, housing, education and work, and opportunities for participation, including expressing views about their care [57]. For service users with long stays in secure hospitals, recovery involves maintaining as high a quality of life as possible. Some forensic service users achieve recovery through involvement in sports or the Arts, including creative writing [100], singing [101], and courses in Recovery Colleges [102]. Walker, et al. (2013) outline how FMH nurses can apply recovery principles in "community day leaves" with service users [103]. Pets, including "therapy dogs" can also contribute to recovery [104,105]. However, research in one high secure hospital found possible conflicts between recovery and security [106].

Another study found that a lack of "autonomy and choice" and meaningful relationships impeded recovery in a secure hospital [107]. In the UK, most service users in secure hospitals are deprived of close relationships and sexual fulfillment, particularly if they are inpatients for several years [108]. Quinn, et al. (2015) comment on the "need for...research to consider...benefits and risks" of forensic service users' "sexual relationships". Ethical arguments for and against forensic inpatients developing intimate relationships have been considered, including rights for fulfillment; and issues of safety, related to many service users' vulnerability, their danger of being exploited; and the need for sexual health promotion [108].

\section{Physical Health Needs}

There is evidence that many forensic service users have poor physical health [109], including people experiencing personality disorder, who are more likely than most people to have hypertension, cardiovascular diseases, accidents and sexually transmitted diseases [93]. Amongst other studies, researchers describe "physical health care plans", including diet and exercise, in a secure hospital [110], and programmes to help forensic service users stop smoking [111] and enjoy regular exercise [52].

\section{Ethical Problems and Perspectives}

FMH nursing involves various ethical problems, including the balance between service users' needs for autonomy and rehabilitation versus protecting the public, related to the "security versus therapy debate", considered earlier in this article. Another ethical problem concerns FMH nurses' involvement "in...physical security", for example, room checks to ensure there are no unsafe items and having service users handcuffed to them on visits to courts [74]. Price, et al. (2012) concluded, from their research, that effects of FMH nurses' security tasks on therapeutic relationships were minimised by sensitive, non-authoritarian communication [112].

Ethical problems in FMH nursing can be understood by examining them from the perspectives of sociological conflict and consensus theorists [113]. Conflict theorists emphasize staff "surveillance" and "power" over service users [114,115]. In contrast, consensus theory, reflected in many texts on FMH nursing, stresses both benefits of care and treatment to the service user and public safety, with nurses and other professionals aiming to enable service users to regain power and freedom [74]. In the author's experience, both conflict and consensus theories can help in understanding, and resolving, ethical problems. An understanding of conflict theories can help FMH nurses avoid unnecessary restrictions [4] and address power imbalances in nurse-service user relationships [116]. Conflict theorists are more likely to hold absolutist beliefs: that, for example, detention in secure hospitals is always wrong [117]. FMH nurses, and other staff using approaches influenced by consensus theory, are more likely to adopt utilitarian ethical perspectives, with decisions ensuring the greatest good, and/or the least harm, to both the service user who is violent and other people, including the public [74]. However, conflict theorists would argue that "improvements" to care in secure hospitals do not reduce their essentially coercive nature [118].

\section{Cognitive Behavioral Therapy (CBT)}

Finally, this paper will consider CBT used by FMH nurse therapists. Other forms of psychotherapy [23] are not considered because of lack of space. Specialist interventions for people with a diagnosis of schizophrenia include CBT, often combined with antipsychotic medication [119], administered and carefully monitored by FMH nurses. In CBT, nurses and other professionals 


\section{Nursing \& Healthcare International Journal}

make precise measurements of problems and symptoms, and facilitate interventions to reduce these. CBT also involves assessing service users' "strengths and positive coping strategies" [53] For example, a service user who is distressed by voices telling him to assault people, could be asked to rate their frequency and intensity on scales of 1 to 10 before and after targeted interventions. The latter could include techniques to help him relax, and distract himself from the voices: for example, through listening to his favorite music, or engaging in activities that he finds enjoyable [120].

Other interventions that could be helpful, include talking to a FMH nurse about distressing experiences, and safe space on the ward, away from situations that, like many people with schizophrenia, this service user finds stressful or threatening, such as noise and large numbers of people. As he gradually recovers, a CBT technique called graded exposure could be used to enable him to get used to, and enjoy, others' company. Psychoeducation might be available for this individual, and with his agreement, his family, to discuss ways to cope with voices and other distressing symptoms [54,120].

One systematic review and meta-analysis found evidence that CBT is effective for people experiencing "positive symptoms in schizophrenia" [121], but another similarly detailed review concluded that CBT was no more effective for these symptoms than "non-specialized therapy" [122]. However, positive results have been reported for CBT used with service users who have committed arson [123], sexual offences [124] and who have problems managing anger [125]. Anger management using CBT involves records of incidences and types of violence and aggression, and individual or group problem solving. In the latter, service users identify causes of, and contributory factors to, violent acts, and consider their expression of anger, and more effective ways of managing anger-provoking situations. In problem solving groups, service users receive positive feedback and suggestions from their peers and from nurses and other professionals $[126,127]$. Service users described benefits from an anger management course, including: recognising triggers that precipitated aggressive thoughts, feelings or actions; walking away from situations evoking anger, and returning to them later; and seeking "clarification" to correct "misinterpretation of events" [128]. Taft, et al. (2012) discuss professional skills in anger management groups with war veterans, including: enabling service users to recognise their positive coping strategies, and to learn from incidents where they expressed anger aggressively; and helping service users to appreciate progress by inviting them to contrast ways they handled an incident in the present with how they would have responded in the past [127].

\section{Limitations and Conclusion}

Most of the current literature on FMH nursing, in databases and other sources reviewed, is based on Western ideas about nursing care, including communication with service users. It is not clear how far this literature is applicable to FMH nursing and forensic service users' experience in other countries. Another limitation of the current survey of the literature, is that it is not a systematic review. Further studies could include systematic reviews of a wider range of databases, including the literature of countries other than those in North America, Europe and Australasia.

Literature reviewed includes accounts, and a few research studies, of FMH nurses' roles in the community, and in liaison and diversion services, prisons and prison aftercare. Over 200 risk assessment tools have been devised, although it has been argued that not all of them are reliable and valid. Nurses have been involved in producing and validating some of these tools. Much of the (often descriptive) literature on FMH nursing is on risk assessment and management. Some researchers have described adverse effects to service users from excessive risk management.

There is research-based evidence of the importance of communication to forensic service users, and of beneficial social environments. Research findings indicate the importance of FMH nurses' self-awareness, and there are accounts of important aspects of effective communication and therapeutic relationships, based on clinical experience. Aspects of holistic care are described in some of the FMH nursing literature. Overall, this area does not appear to have been widely researched, but there have been several studies on forensic service users' physical health, recovery in secure hospitals, trauma-informed care, and projects to reduce seclusion. Ethical issues, particularly concerning the "security/custody versus therapy debate", have been debated. Finally, nurses' use of CBT with forensic service users experiencing schizophrenia has been described, with mixed conclusions, based on systematic reviews and metaanalyses, of its efficacy. CBT has been found to be effective for anger management.

\section{References}

1. Kettles AM, Byrt R, Woods P (2007) Introduction. In: National Forensic Nurses' Research and Development 


\section{Nursing \& Healthcare International Journal}

Group (Eds), Forensic Mental Health Nursing: Forensic Aspects of Acute Care. London, UK: Quay Books/MA Healthcare, Ltd.

2. Varshney M, Mahapatra A, Krishnan V, Gupta R, Koushiv SD (2016) Violence and mental illness: What is the true story? J Epidemiology 70(3): 223-225.

3. Gournay K, Benson R, Rogers P (2008) Inpatient care and management. In: Soothill $\mathrm{K}$, et al. (Eds), Handbook of Forensic Mental Health. Uffculme, UK: Willan Publishing.

4. Byrt R, Spencer Stiles TA, Ismail I (2018) Evidence based practice in forensic mental health nursing: A critical review. J Fors Nurs 14(4): 223-229.

5. Jack HE, Fricchione G, Chibanda D, Thornicroft G, Machando, et al. (2018) Mental health of incarcerated people: A global call to action. The Lancet Psychiatry 5(5): 391-392.

6. Pun JKN, Chan EA, Wang S, Slade D (2018) Health professional-patient communication practices in East Asia: An integrative review of an emerging field of research and practice in Hong Kong, South Korea, Taiwan and mainland China. Patient Educ Couns 101(7): 1193-1206.

7. Baker J, Coffey M, Doyle M (2011) Helping people with mental health problems who come into the criminal justice system. In: Pryjmachuk S (Ed), Mental Health Nursing. An Evidence-Based Introduction, London, UK, Sage.

8. HM Government (1983) Mental Health Act, 1983, London, UK, HMSO.

9. Dean E (2013) Nurses work with police to cut unnecessary arrests. Mental Health Pract 17(1): 8-9.

10. Evans R (2014) Caring in court. In: Norman A, et al. (Eds), Nursing in Criminal Justice Services. Keswick, UK: M\&K Publishing, pp: 41-54.

11. Leicestershire Police (2018) Praise for Leicestershire's mental health triage service. Available at: http://www.leics.police.uk/newsappeals/news/2018/H/27/praise-for-leics.

12. Hurley J, Linsley P, Elvins M, Jones M (2013) Nurses leading care in custody suite environments: A qualitative study from Scotland. J Fors Nurs 9(1): 4551.
13. McKenna A, Furness T, Oakes J, Brown S (2015) Police and mental health clinician partnership in response to mental health crisis: A qualitative study. Int J Mental Health Nurs 24(5): 386-393.

14. Glasper A (2014) Mental health nurses to work with police stations and courts. Brit J Nurs 23(2): 174-175.

15. Goornany A, Dickinson T (2015) The influence of prison climate on the mental health of adult prisoners: A literature review. J Psychiatric and Mental Health Nurs 22(6): 413-422.

16. Warren M (2015) Mental health care beyond prison. Brit J Nurs 24(15): 790-791.

17. HM Chief Inspector of Prisons for England and Wales (2018) Annual Report, 2017-2018.

18. Gorman G, Singer RM, Christmas E, Herbstritt C, Miller $\mathrm{L}$, et al. (2018) In a spirit of resolution: Phenomenology of nursing practice and the criminal justice system. Adv in Nurs Sci 41(2): 105-117.

19. Goshin LS, Colbert AM, Carey JF (2018) Research to improve health equality and human rights for criminal-justice involved people. J Fors Nurs 14(2): 53-60.

20. Penal Reform International and Thailand Institute of Justice (2018) Global Prison Trends, London, UK, Penal Reform Trust.

21. HM Government (2005) Criminal Justice Act. London, UK, The Stationery Office.

22. HM Government (2007) Mental Health Act. London, UK, The Stationery Office.

23. Aiyegbusi A, Clarke Moore J (2009) Therapeutic Relationships with Offenders. An Introduction to the Psychodynamics of Forensic Mental Health Nursing. Jessica Kingsley, London, UK, Jessica Kingsley and delete 13, [3], 213-214.

24. De Burca C, Miles HL, Vasquez EA (2013) Substance use amongst mentally disordered offenders in medium security: Prevalence and relationship to offending behaviour. J Psychiatric Pract 15(4): 259268.

25. Byrt R, Wray C, Tom (2005) Towards hope and inclusion: Nursing interventions in a medium secure 
service for men with personality disorders. Mental Health Pract 8(8): 38-43.

26. Mason T, Mercer D (1998) Critical Perspectives in Forensic Care: Inside Out. Basingstoke, UK: Macmillan.

27. Coffey M, Byrt R (Eds.) (2010) Forensic Mental Health Nursing. Ethics, Debates, Dilemmas, London, UK, Quay Books/Mark Allen Healthcare, Ltd.

28. Woods P (2009) Risk to others. In: Woods P, et al. (Eds), Risk Assessment and Risk Management in Mental Health Nursing. Oxford, UK: Wiley-Blackwell, pp: 109-142.

29. Allen E (2015) See, Think, Act. Your Guide to Relational Security. London, UK, Royal College of Psychiatrists Centre for Quality Improvement.

30. Royal Society (1992) Risk: Analysis, Perception, Management. London: Royal Society. Quoted in: Cordall J (2009) Risk assessment and management. In: Woods P, et al. (Eds.), Risk Assessment and Risk Management in Mental Health Nursing. Oxford, WileyBlackwell, UK, pp11.

31. Spooner M (2015) Working in Secure Forensic Settings. A Care Quality Guide for Support Workers and Staff. Hove, Pavilion Publishing, UK.

32. Campbell D (2017) Thousands of mental health patients spend years on secure wards. The Guardian.

33. Blumoroti OJ, Forrester A, Wilson S, Dewhurst J (2009) Mentally ill prisoners in need of urgent hospital transfer: Appeal panels should resolve disputes to reduce delays. J Fors Psychiatry \& Psychol 20 (1): S5-S10.

34. Fazel S, Wolf A (2018) Screening a risk assessment tool to use in practice: A ten-point guide. EvidenceBased Mental Health 2(2): 41-43.

35. Dickens G (2015) Re-focusing risk assessment in forensic mental health nursing. J. Psychiatric and Mental Health Nurs 22(7): 461-462.

36. Gunenc C, O Shea LE, Dickens GL (2015) Prevalence and predictors of verbal aggression in a secure mental health service: use of the HCR-20. Internat J Mental Health Nurs 24(4): 314-323.
37. Webster CD, Douglas KS, Eaves D, Hart CD (1997) HCR-20: Assessing Risk for Violence: Version 2. Burnaby, Canada: Mental Health, Law and Policy Institute, Simon Fraser University. Cited in: Woods P, et al. (Eds), Risk Assessment and Risk Management in Mental Health Nursing. Oxford, UK: Wiley-Blackwell, pp: 91.

38. Arai K, Takano A, Nagata T, Hirabayashi N (2017) Predicting accuracy of the Historical-Clinical-Risk Management-20 for violence in psychiatric wards in Japan. Crim Behaviour and Mental Health 27(5): 409420.

39. British Columbia (BC) Mental Health and Substance Use Services (2013) Short-Term Assessment of Risk and Treatability (START) Vancouver, Canada: BC Mental Health and Substance Use Services. Quoted in: Dickens G (2015) Editorial. Re-focusing risk assessment in forensic mental health nursing. J Psychiatric and Mental Health Nurs 22: 461-462.

40. Woods P (2009) Risk to others. In: Woods P, et al. (Eds), Risk Assessment and Risk Management in Mental Health Nursing. Oxford, UK: Wiley-Blackwell, pp: $109-142$.

41. Department of Health (2007) Best Practice in Managing Risk. London, UK, Department of Health.

42. Sender-Galloway S, Clark T (2013) Problematic substance use among forensic psychiatric community patients. J Fors Pract 15(2): 119-129.

43. Witt K, van Dorn R, Fazel S (2013) Risk factors for violence in psychosis: Systematic review and metaregressive analysis of 110 studies. PLoS ONE 8(2): e55942.

44. Schaefer R, Daffern M, Ferguson AM (2011) The prevalence and manifestation of substance use paralleling behaviours in a secure forensic psychiatric hospital. Mental Health and Substance Use 4(4): 327339.

45. Gamble C, Ryrie I, Curthoys J (2009) Psychosocial Interventions. In: Norman I, et al. (Eds), The Art and Science of Mental Health Nursing $2^{\text {nd }}$ (Edn.), Maidenhead, McGraw Hill Open University Press, UK.

46. Saunders A, Browne D, Durcan G (2013) Briefing. The Bradley Commission. 1. Black and minority ethnic communities. Mental health and criminal justice. Centre for Mental Health: London, UK, pp: 1-15. 


\section{Nursing \& Healthcare International Journal}

47. Coffey M (2012) A risk worth taking? Value differences and alternative risk constructions in accounts given by patients and their community workers following conditional discharge from forensic mental health services. Health, Risk and Society 14(5): 465-482.

48. Heyman B, Godin PM, Reynolds L, Davies JP (2013) Assessing the probability of patients reoffending after discharge from low to medium secure forensic mental health services: An inductive prevention paradox. Health, Risk and Society 15(1): 84-102.

49. Reynolds LM, Jones JC, Davies JP, Freeth D, Heyman B (2014) Playing the game: Service users' management of risk status in a UK medium secure forensic mental health service. Health, Risk and Society 16(3): 199209.

50. Mason T, Chandley M (1990) Nursing models in a special hospital: A critical analysis of efficacy. J Adv Nurs 15: 667-673.

51. Bose S (2009) Containment and the structured day. In: Aiyegbusi A, et al. (Eds), Therapeutic Relationships with Offenders. An Introduction to the Psychodynamics of Forensic Mental Health Nursing. London, UK, Jessica Kingsley, pp: 105-125.

52. Tetlie T, Heimsnes MC, Almvik R (2009) Using exercise to treat patients with severe mental illness. How and why? J Psychosocial Nurs and Mental Health Servs 4(2): 33-40.

53. Schalast N, Tonkin M (2016) The Essen Climate Evaluation Schema (EssenCES). A Manual and More. Boston, USA: Hogrefe Publishing.

54. Ford K, Byrt R, Dooher J (2010) Preventing and Reducing Aggression and Violence in Health and Social Care. A Holistic Approach. Keswick, UK: M\&K Publishing.

55. Byrt R, Hardie T (2007) Cultural competence and patients' rights. In National Forensic Nurses' Research and Development Group (Eds.). Forensic Mental Health Nursing: Forensic Aspects of Acute Care. Quay Books/MA Healthcare, Ltd, London, UK.

56. Askola R, Nikkonen M, Paavilainen E, Soininen P, Putkonen H, et al. (2018) Forensic psychiatric patients' perspectives on their care: A narrative view. Perspectives in Psychiatric Care 54(1): 64-73.

Byrt R. Forensic Mental Health Nursing in Secure Hospitals and the Criminal Justice System. Nurs Health Care Int J 2019, 3(2): 000176.
57. McKeown M, Edgar F, Callaghan I (2017) Services for people requiring secure forms of care. In: Chambers M (Eds), Psychiatric and Mental Health Nursing. The Craft of Caring. Abingdon, UK, Routledge, Taylor and Francis Group, pp703-714.

58. Mercer D, Mason T, Richman J (1999) Good and evil in the crusade of care. J Psychosocial Nurs and Mental Health Servs 37(9): 13-17.

59. Bowers L (2002) Dangerous and Severe Personality Disorder. Response and Role of the Psychiatric Team, London, UK: Routledge.

60. Harris DM, Happell B, Manias E (2015) Working with people who have killed: The experience and attitudes of forensic mental health clinicians working with forensic patients. Int J Mental Health Nurs 24(2): 130138.

61. Walsh E (2010) The emotional labour of prison nursing. In: Coffey, M., Byrt, R. (Eds.). Forensic Mental Health Nursing: Ethics, Debates, Dilemmas, London, UK, Quay Books/MA Healthcare, Ltd., pp139-153.

62. Doyle P, Quayle E, Newman E (2017) Social climate in forensic mental health settings: A systematic review of qualitative studies. Aggression and Violent Behavior 26: 118-136.

63. Salzmann Erikson M, Rydlo C, Wiklund Gustin L (2016) Getting to know the person behind the illness - The significance of interacting with patients hospitalized in forensic psychiatric wards. J Clin Nurs 25(9-10): 1426-1434.

64. Bowen M, Mason T (2012) Forensic and non-forensic psychiatric nursing skills and competencies for psychopathic and personality-disordered patients. J Clin Nurs 21(23-24): 3356-3564.

65. Thomas P, Bracken P, Timini S (2013) The anomalies of evidence-based medicine in psychiatry: Time to rethink the basis of mental health practice. Mental Health Review J 17(3): 152-162.

66. Yakeley J, Wood H (2011) Patients' experiences of forensic psychotherapy. Psychoanalytic Psychotherapy 25(1): 105-114.

67. Ian (2017) Ian's story: user involvement and shared decision making. In: McKeown, et al., Services for people requiring secure forms of care. In: Chambers M (Ed.), Psychiatric and Mental Health Nursing. The 


\section{Nursing \& Healthcare International Journal}

Craft of Caring. Abingdon, UK, Taylor and Francis Group.

68. Walker J (2014) Recovery and redemption. In: Norman A, et al. (Eds), Nursing in Criminal Justice Services. Keswick, UK, M\&K Publishing, pp: 5-15.

69. Rolfe G (1998) The theory-practice gap in nursing: from research-based practice to practitioner-based research. J Adv Nurs 3: 672-679.

70. Rogers C (1967) On Becoming a Person: A Therapist's View of Psychotherapy, London, UK, Constable.

71. Barone F (2010) My personal tsunami: Surviving assault. In: Coffey M, et al. (Eds), Forensic Mental Health Nursing. Ethics, Debates, Dilemmas. London, UK: Quay Books, MA Healthcare, Ltd, pp: 71-80.

72. Wood, J. (2010). From hero, to hospital, to hope: A carer's experience. In: Coffey M, et al. (Eds), Forensic Mental Health Nursing. Ethics, Debates, Dilemmas, London, UK, Quay Books/MA Healthcare, Ltd, pp: 8184.

73. Kunyck D, Olsen JK (2001) Clarification of conceptualisations of empathy. J Adv Nurs 35(3): 317-325.

74. Byrt R (2010) Ethical principles in forensic and prison nursing. In: Coffey M, et al. (Eds), Forensic Mental Health Nursing. Ethics, Debates, Dilemmas. London, UK, Quay Books/MA Healthcare, Ltd. pp: 1741.

75. Byrt R, Aiyegbusi T, Hardie T, Addo M (2007) Cultural and diversity issues. In: National Forensic Nurses' Research and Development Group (Eds.). Forensic Mental Health Nursing: Interventions with People with Personality Disorder. London, UK, Quay Books, MA Healthcare, Ltd., pp219-233.

76. Maguire T, Daffern M, Martin T (2014) Exploring nurses' and patients' perspectives of limit-setting in a forensic mental health setting. Int J Mental Health Nurs 23(2): 153-160.

77. Morrison EF (1992) A coercive interactional style as an antecedent to aggression in psychiatric patients. Research in Nurs and Health 15(6): 421-431.

78. Fulford KWM (2004) Facts/values: Ten principles of values-based medicine. In Radden J (Ed), The

Byrt R. Forensic Mental Health Nursing in Secure Hospitals and the Criminal Justice System. Nurs Health Care Int J 2019, 3(2): 000176.
Philosophy of Psychiatry: A Companion. Oxford, UK, Oxford University Press, pp205-234.

79. Gildberg FA, Paaske KJ, Rasmussen VL, Nissen RD, Bradley SK, et al. (2016) Humor: power conveying social structures inside forensic mental health nursing. J Fors Nurs 12(3): 120-128.

80. Bartlett A, Jhanji E, White S, Hart A, Scammell J, et al. (2015) Interventions with women offenders: A systematic review and meta-analysis of mental health gain. J Fors Psychiatry and Psychol 26(2): 133-165.

81. Lees N, Withington J (2001) Involving service users. In: Dale C, et al. (Eds), Forensic Mental Health. Issues in Practice. Edinburgh, UK, Bailliere Tindall, Royal College of Nursing, pp109-126.

82. Byrt R, James L (2007) Towards therapeutic environments: Challenges and problems. In: National Forensic Nurses' Research and Development Group. (Eds), Forensic Mental Health Nursing: Interventions with People with "Personality Disorder". London, UK, Quay Books, MA Healthcare, Ltd., pp29-49.

83. Lehoczki A, Halmai T (2016) Homicide offenders with or without psychotic disorders: Post-traumatic symptoms, guilt and shame, and coping in the postoffence period. Annals of Forensic Research and Analysis 3(2): 1031-1036.

84. Bailey T, Alvarez Jimenez M, Garcia Sanchez AM, Hulbert C, Barlow E, et al. (2018) Childhood trauma is associated with severity of hallucinations and delusions in psychotic disorders: A systematic review and meta-analysis. Schizophrenia Bull 44(5): 11111122.

85. Vollm B, Nedophil N (2016) The Use of Coercive Measures in Forensic Psychiatric Care. Legal, Ethical and Practical Challenges. Cham, Springer, Switzerland.

86. Agenda (Alliance for Women and Girls at Risk) (2017) Agenda Briefing on the Use of Restraint amongst Women and Girls. London, UK: Agenda.

87. Meehan T, McIntosh W, Bergen H (2006) Aggressive behaviour in high-secure settings: The perceptions of patients. J. of Psychiatric and Mental Health Nurs 13(1): 19-25.

88. Smith GM, Ashbridge DM, Altenor A, Steinmetz W, Davis RH, et al. (2015) Relationship between seclusion and restraint reduction and assaults in 


\section{Nursing \& Healthcare International Journal}

Pennsylvania's forensic services centers, 2001-2010. Psychiatric Servs 66(12): 1326-1332.

89. Ching H, Daffern M, Martin T, Thomas S (2010) Reducing the use of seclusion in a forensic psychiatric hospital: assessing the impact of agency, therapeutic climate and staff confidence. J Psychiatric and Mental Health Nurs 21(5): 737-760.

90. Keski Valkama A, Koivisto AM, Eronen M, Riittakerttu KM (2010) Forensic and general psychiatric patients view of seclusion: A comparsion study. J Fors Psychiatry and Psychol 22(3): 446-461.

91. Doyle M, Jones P (2013) Hodges' Health Career Model and its role and potential application in forensic mental health nursing. J Psychiatr Ment Health Nurs 20(7): 631-640.

92. Byrt R (2008a) Power and participation in forensic services: An introduction. In National Forensic Nurses' Research and Development Group (Eds.). Forensic Mental Health Nursing: Competencies, Roles, Responsibilities. London, UK, Quay Books/MA Healthcare, Ltd., pp77-97.

93. Byrt R (2013) Forensic nursing interventions with patients with personality disorder: A holistic approach. J Fors Nurs 9(3): 181-187.

94. Blofeld Sir J (2003) Independent Inquiry into the Death of David Bennett. An Independent Inquiry Set Up Under HSG (94) 27, London, UK, Department of Health.

95. Blom Cooper, Sir Louis (1992) Report of the Committee of Inquiry into Ashworth Hospital. London, UK: HMSO 1(2).

96. Read M, McCrae N (2016) Preventing suicide in lesbian, gay, bisexual and transsexual prisoners: A critique of UK policy. J Fors Nurs 12(1): 13-18.

97. Addo M (2006) Culture, spirituality and ethical issues in caring for clients with personality disorder. In: National Forensic Nurses' Research and Development Group (Eds.). Aspects of Forensic Mental Health Nursing: Interventions with People with "Personality Disorder". Quay Books, Mark Allen Health Care, Ltd, London, UK, pp: 60-80.

98. Addo M (2010) Ethical and legal issues of culture, spirituality, diversity and equality in forensic nursing. In: Coffey M, et al. (Eds.), Forensic Mental Health
Nursing. Ethics, Debates, Dilemmas. London, UK, Quay Books/MA Healthcare, Ltd, pp: 85-106.

99. Perkins R, Repper J (2013) Recovery and social inclusion. In: Norman I, et al. (Eds), The Art and Science of Mental Health Nursing. Principles and Practice. Maidenhead, UK, Open University Press/McGraw Hill Education, p60.

100. Solanki M, Byrt R (2003) Finding a voice. Writing and empowerment. In: Dooher J, et al. (Eds), Empowerment and the Recipients of Health Care. Dinton, Salisbury, UK, Quay Books/Mark Allen Healthcare, pp: 204-219.

101. Merrick I, Maguire A (2017). From let it be to it must be love: the development of a choir for patients and staff at a high secure hospital. Arts and Health: Int J. Research, Policy and Pract 9(1): 73-80.

102. Frayn E, Duke J, Smith H, Wayne P, Roberts G (2016) A voyage of discovery: Setting up a recovery college in a secure setting. Mental Health and Social Inclusion 20(1): 29-35.

103. Walker A, Farnworth L, Lapinski S (2013) A Recovery perspective on community day leaves. J. Fors Pract 15(2): 109-118.

104. Dell CA, Poole N (2015) Taking a PAWS to reflect on how the work of a therapy dog supports a traumainformed approach to Prisoner Health. J Fors Nurs 11(3): 167-173.

105. Mercer J, Gibson K, Clayton D (2015) The therapeutic potential of a prison-based animal programme in the UK. J Fors Pract 17(1): 43-54.

106. Cromar Hayes M, Chandley M (2015) Recovery in a high secure hospital in England. Mental Health Pract 18(8): 22-27.

107. Reavey P, Brown SD, Kanyeredzi A, McGrath, Tucker I (2019) Agents and spectres: Life-space on a medium secure forensic psychiatric unit. Soc Sci and Med 220: 273-282.

108. Quinn C, Happell B (2015) Consumer sexual relationships in a forensic mental health hospital. Perceptions of nurses and consumers. Int J Mental Health Nurs 24: 121-129. 


\section{Nursing \& Healthcare International Journal}

109. Cormac I, Ferriter M, Benning R, Saul C (2005) Physical health and risk factors in a population of long stay patients. Psychiatric Bulletin 29(1): 18-20.

110. Haddad M (2011) Improving the physical health of people with severe mental illness in a low secure forensic unit. Int J Mental Health Nurs 25(6): 554-565.

111. Dickens GL, Staniford J, Long CG (2014) Smoking behaviour, motives, motivation to quit and selfefficacy among patients in a secure mental health service: Comparison with staff controls. J Psychiatric and Mental Health Nurs 21(6): 483-490.

112. Price 0, Wibberley C (2012) An exploratory study investigating the impact of procedures used to manage patient substance misuse. J Psychiatric and Mental Health Nurs 19(8): 672-680.

113. Byrt R (2008b) Negative control or lifesaving? Perspectives on power. In: National Forensic Nurses' Research and Development Group (Eds.). Forensic Mental Health Nursing: Competencies, Roles, Responsibilities. London, UK, Quay Books, MA Healthcare, Ltd., pp99-125.

114. Foucault M (1991) Discipline and Punish. The Birth of the Prison. Translated from the French by Alan Sheridan. Harmondsworth, UK, Penguin Books.

115. Jacob JD, Foth $\mathrm{T}$ (2013) Expanding our understanding of sovereign power: on the creation of zones of exclusion in forensic psychiatry. Nurs Philos 14(3): 178-185.

116. Schafer P, Peternelj Taylor C (2003) Therapeutic relationships and boundary maintenance: the perspective of forensic patients enrolled in a treatment program for violent offenders. Issues in Mental Health Nurs 24(6-7): 605-625.

117. Szasz T (2011) The myth of mental illness: 50 years later. The Psychiatrist 35(5): 179-181.

118. Bull P, Gadsby J, Williams S (2018) Critical Mental Health Nursing. Monmouth, UK: PCCS Books.

119. National Institute for Health and Care Excellence (NICE) (2014) Psychosis and Schizophrenia in Adults: Present Management. Clinical Guidance (CG 178) London, UK: NICE.

120. Byrt R (2007) Towards therapeutic environments: alternatives and solutions. In: National Forensic
Nurses' Research and Development Group (Eds.). Forensic Mental Health Nursing: Forensic Aspects of Acute Care. London, UK, Quay Books, MA Healthcare, Ltd, pp: 51-70.

121. Bighelli I, Salanti G, Huhn M, Schneider Thoma J, Krause M (2018) Psychological interventions to reduce positive symptoms in schizophrenia: Systematic review and meta-analysis. World Psychiatry 17(3): 316-329.

122. Kennedy L, Xyrichis A (2017) Cognitive behavioral therapy compared with non-specialized therapy for alleviating the effect of auditory hallucinations in people with reoccurring schizophrenia: A systematic review and meta-analysis. Community Mental Health J 53(2): 127-133.

123. Tyler N, Gannon TA, Lockerbie L, Ó Ciardha C (2018) An evaluation of a specialist firesetting treatment programme for male and female mentally disordered offenders. Clin Psychol Psychotherapy 25(3): 388400.

124. Mpofu E, Athanasou JA, Rafe C, Belshaw SH (2018) Cognitive-behavioral therapy efficacy for reducing recidivism rates of moderate and high-risk sexual offenders: A scoping systematic literature review. Int J Offender Ther Comp Criminol 62(1): 170-186.

125. Fernandez E, Malvaso C, Day A, Guharajan D (2018) $21^{\text {st }}$ century cognitive-behavioral therapy for anger: A systematic review of research design, methodology and outcome. Behav Cogn Psychother 46(4): 385-404.

126. Bowness S, Algy Byrt R, Ngeh R, Mason L, Wray C (2008) Managing angry creatively: An overview. In National Forensic Nurses' Research and Development Group (Eds.). Forensic Mental Health Nursing: Competencies, Roles, Responsibilities. London, UK, Quay Books, MA Healthcare, Ltd., pp221-235.

127. Taft CT, Creech SK, Kachadourian L (2012) Assessment and treatment of post-traumatic anger and aggression: A review. J Rehabil Res Dev 49(5): 777-788.

128. Colm, Algy, Dirk, Ezra, Ferg, Byrt, R (2008) Managing angry creatively: Patients' views and experiences. In National Forensic Nurses' Research and Development Group. Forensic Mental Health Nursing: Competencies, Roles, Responsibilities. UK: Quay Books, MA Healthcare, Ltd., pp237-246. 